\title{
A Racionalidade e o Debate Ambiental Contemporâneo
}

\author{
The Rationality and Contemporary Environmental Debate
}

José Edmilson de Souza Lima1

\section{Resumo}

Nas entrelinhas do debate ambiental contemporâneo estão escondidos e revelados valores, crenças e práticas que podem ser caracterizados como expressões de uma racionalidade. Nesse contexto, o artigo se propõe a ensaiar respostas para as seguintes indagações: o que é a razão? É possível pensar uma racionalidade ambiental não centrada no mercado? Ou, que não sirva de legitimação ideológica da sociedade centrada no mercado? Para tanto, na primeira parte reconstitui as origens clássicas do conceito de razão; na segunda, explicita o processo de formação e consolidação da racionalidade instrumental moderna e da marginalização da racionalidade substantiva; na terceira, resgata a reconstituição da racionalidade substantiva como possibilidade objetiva de ampliação dos espaços para a autorealização humana; na quarta, torna visíveis algumas conexões entre substantividade humana e racionalidade ambiental; e, finalmente, conclui parcialmente que racionalidade ambiental, entendida como racionalidade alternativa de produção, não pode estar centrada no mercado.

Palavras-chave: Razão. Racionalidade Instrumental. Racionalidade Substantiva. Racionalidade Ambiental.

\begin{abstract}
In the subtext of the contemporary environmental debate are hidden and restores values, beliefs and practices that can be characterized as expressions of rationality. In this context, the article proposes to rehearse answers for the following questions: what is reason? Is it possible to think an environmental rationality that is not centered on the market? Or, that does not serve as ideological legitimation of the society centered on the market? To this end, the first part reviews the origins of the classical concept of reason; in the second one, it explains the process of formation and consolidation of modern instrumental rationality and the marginalization of substantive rationality; in the third one, it rescues the reconstitution of rationality substantive as an objective possibility of expansion of spaces for human selfrealization; in the fourth one, it makes visible some connections between human substantivity and environmental rationality; and finally, it concludes in part that environmental rationality, which is understood as an alternative rationality of production, cannot be centered on the market.
\end{abstract}

Key words: Reason. Instrumental Rationality. Substantive Rationality. Environmental Rationality.

\footnotetext{
1 Sociólogo. Doutor em Meio ambiente e Desenvolvimento (MADE-UFPR). Pesquisador/docente do Mestrado em Organizações e Desenvolvimento da FAE. E-mail para contato: edmilson@fae.edu.
}

Esta obra foi licenciada com uma Licença Creative Commons - Atribuição 3.0 Não Adaptada. 
Muitos, dentre nós, conhecem adolescentes dominados pela compulsão da comida. O comedor compulsivo, que se empanturra com tanta pressa e com tanta desatenção que mal repara naquilo que devora, aplica a si mesmo duas sérias penalidades. Embora seu corpo esteja sendo abarrotado de enormes quantidades de coisas realmente boas, o comedor vai-se tornando, ao mesmo tempo, cada vez menos capaz, fisicamente. $E$ que pena! - nem está apreciando aquilo que come; mal se lembra de procurar sentir o sabor da comida.

Como adultos do século $X X$, nós nos tornamos usuários compulsivos - chegando aproximadamente aos mesmos resultados (WALTER KERR, The Decline of Pleasure).

\section{Introdução}

As reflexões contidas neste artigo se situam no centro do debate contemporâneo acerca da crise civilizatória, com rebatimentos em todas as dimensões da vida associativa e que reivindica novas atitudes, novas epistemes, novas teorias e novos saberes. A categoria que confere unidade ao texto é a de racionalidade, apreendida em seus dois sentidos, o instrumental e o substantivo. Trata-se de uma categoria analítica relacional, pois não parece ser possível compreender a dimensão instrumental da racionalidade sem seu complemento, a dimensão substantiva. Nesse sentido, toda discussão da racionalidade substantiva, tomada a partir da obra de Guerreiro Ramos, traz de forma subjacente a contribuição de Polanyi (1980 e 1994) acerca do conceito de uma "economia do suficiente". Esse conceito alternativo de economia está centrado em uma racionalidade substantiva, pois há predomínio de relações de vizinhança e de fortalecimento do tecido social, capaz de garantir a sobrevivência dos componentes do grupo social. Polanyi ressalta que a economia é claramente apenas um meio de garantir o fim de um sistema social, o bem-estar dos viventes. A contribuição de Guerreiro Ramos tem como um dos pontos de partida, dentre outros, esta concepção de Polanyi.

A outra categoria analítica é a de racionalidade ambiental, derivada da contribuição de Leff, cujos pontos de partida são as obras de Marx, Weber e Foucault. A racionalidade ambiental emerge nas formulações de Leff como todos os valores, crenças, sentimentos e saberes que resistem ao poder colonizador da racionalidade instrumental.

A contribuição deste artigo está associada à tentativa de aproximar estas duas abordagens que, embora de formas diversas, enfrentam a complexidade da 
crise contemporânea e, em função disto, dão pistas para novas formas de produzir conhecimento com preocupações práticas.

O artigo, além da introdução e das considerações finais, está organizado em quatro seções. Na primeira, são apresentadas as "origens clássicas da razão e seus desdobramentos modernos"; na segunda, discute alguns dos elementos fundantes da "razão moderna"; na terceira, são apresentados os principais elementos constitutivos da "racionalidade ambiental"; e, na quarta e última seção, tal como na terceira, são apresentados os principais elementos constitutivos da "racionalidade ambiental".

\section{Origens Clássicas da Razão e seus Desdobramentos Modernos}

Não existem duas ou mais "razões", mas apenas a Razão humana. Assim pensavam os primeiros seres humanos na Grécia antiga que se ocuparam do tema. Não havia distinção, por exemplo, entre a capacidade de calcular e a de ser prudente. Aristóteles, em sua Ética a Nicômaco (VI/XIII, p.10), insistia com a idéia de que a ação prudente pressupõe o cálculo e todo cálculo pressupõe a prudência. Não se pode ser prudente sem ser bom, assim como não se pode ser bom sem ser prudente. O "certo" ou a "justa medida" para Aristóteles é o procedimento mais adequado, sem excessos ou extremismos, de acordo com as circunstâncias. A ação adequada é adquirida a partir do exercício e do hábito; não se age corretamente porque se é virtuoso, mas, ao contrário, tem-se virtude porque se age adequadamente. Nas entrelinhas desta noção de razão está a idéia de que as paixões não se caracterizam como defeitos ou virtudes em si mesmas, mas como possibilidades objetivas - desde que "bem" conduzidas - de auto-realização humana.

Note-se, portanto, que a compreensão clássica acerca da razão tende a associar substantividade com calculabilidade sem hierarquia ou predomínio abusivo de um dos domínios sobre o outro. Outro ponto digno de destaque é que a razão clássica está associada diretamente ao indivíduo, nunca fora dele.

Na formulação de Guerreiro Ramos (1989, p.28), os gregos antigos 
[...] nunca imaginaram a socialidade ${ }^{2}$ como uma condição peculiar ao homem, mas sim uma condição que ele partilhava com outros animais. Os pensadores clássicos estavam preocupados com aquela característica do homem que faz dele uma criatura sui generis, que além de não se incluir completamente no reino natural, reconheciam que essa característica é a percepção que o homem tem da atividade da razão em sua psique. Pelo exercício da razão, e vivendo de acordo com os imperativos éticos dessa razão, o homem transcende a condição de um ser puramente natural e socialmente determinado, e se transforma num ator político.

A condição de ser "humano" não pode ser apreendida a partir de determinismos naturais ou sociais, pois é, em certa medida, um processo contínuo de autonomização, por intermédio da razão, tanto do domínio natural quanto do social. O trecho é um preparativo para a crítica que Guerreiro Ramos elabora à ciência social moderna, que tende a reificar a sociedade, transformando-a em uma instituição puramente natural, com capacidade de gerar padrões definidores da existência humana em todas as dimensões. Nesse trajeto, o ser humano moderno graças a Hobbes (1980) - é reduzido a um ser que simplesmente calcula, que é interesseiro e arrivista.

Para Guerreiro Ramos, é inaceitável a premissa que sustenta a ciência social moderna: a de que a razão está na sociedade e na natureza, não no indivíduo. O autor faz referências à obra The Fable of the bees, de Bernard Mandeville (1714), que compara a sociedade a uma colmeia e que, a partir da obra de Mandeville, os autores modernos passaram a conceber leis racionais para governar a sociedade e a natureza, a despeito de concordarem que as paixões, e não a razão, é que conduziam o ser humano à ação. A noção de Mão invisível, atribuída a Smith (1986), é resultado desse cenário intelectual marcado pela transferência radical da razão do domínio do indivíduo para a sociedade e para a natureza.

Guerreiro Ramos chama a atenção para o fato de que tanto no modelo liberal quanto no socialista, a ciência social formal concebe a vida humana como se fosse ordenada pelo interesse, concebendo a "sociedade" como padrão normativo essencial da existência e da condição humana. Não é por acaso que Durkheim (1988) constrói sua teoria sociológica apoiado na imagem de uma sociedade detentora de todo poder de coerção sobre os indivíduos. Ao afirmar que a sociedade define o "ser social", Durkheim admite que a razão está na sociedade, não no indivíduo. Com base nesse argumento, Durkheim fortalece o dualismo próprio e

\footnotetext{
2 Instinto social.
} 
definidor da era moderna, o instrumental e o substantivo, porém com predomínio do primeiro sobre o último. Ao aceitar como verdade a noção de que a razão está fora do indivíduo humano, Durkheim reduz os espaços para a autorrealização, para a substantividade humana. É como se ele aceitasse a definição de que o ser humano pode ser reduzido às circunstâncias objetivas que o circunscreve.

$\mathrm{Na}$ interpretação de Guerreiro Ramos, um dos problemas da ciência social moderna é aceitar a racionalidade como atributo intrínseco aos processos históricos e sociais. Tal posicionamento é um dos primeiros passos para a distinção própria da modernidade entre racionalidade formal e substantiva. É notável o distanciamento em relação aos gregos antigos, cuja crença na disputa racional, no sentido substantivo, constituía o nexo central da estruturação política da vida, e também o principal suporte para a vida humana associada (Ver Quadro 1).

\section{Quadro 1}

Teoria da vida humana associada

\begin{tabular}{|c|c|}
\hline Formal & Substantiva \\
\hline $\begin{array}{l}\text { I. Os critérios para ordenação das } \\
\text { associações humanas são dados } \\
\text { socialmente }\end{array}$ & $\begin{array}{l}\text { I. Os critérios para a ordenação das } \\
\text { associações humanas são racionais, isto } \\
\text { é, evidentes por si mesmos ao senso } \\
\text { comum individual, independentemente de } \\
\text { qualquer processo particular de } \\
\text { socialização }\end{array}$ \\
\hline $\begin{array}{l}\text { II. Uma condição fundamental da ordem } \\
\text { social é que a economia se transforme } \\
\text { num sistema autorregulado }\end{array}$ & $\begin{array}{l}\text { II. Uma condição fundamental da ordem } \\
\text { social é a regulação política da economia }\end{array}$ \\
\hline $\begin{array}{l}\text { III. O estudo científico das associações } \\
\text { humanas é livre do conceito de valor: há } \\
\text { uma dicotomia entre valores e fatos }\end{array}$ & $\begin{array}{l}\text { III. O estudo científico das associações } \\
\text { humanas é normativo: a dicotomia entre } \\
\text { valores e fatos é falsa, na prática, e, em } \\
\text { teoria, tende a produzir uma análise } \\
\text { defectiva }\end{array}$ \\
\hline $\begin{array}{l}\text { IV. O sentido da história pode ser } \\
\text { captado pelo conhecimento, que se } \\
\text { revela por meio de uma série de } \\
\text { determinados estados empírico- } \\
\text { temporais }\end{array}$ & $\begin{array}{l}\text { IV. A história torna-se significante para o } \\
\text { homem por meio do método paradigmático } \\
\text { de auto interpretação da comunidade } \\
\text { organizada. Seu sentido não pode ser } \\
\text { captado por categorias serialistas de } \\
\text { pensamento }\end{array}$ \\
\hline $\begin{array}{l}\text { V. A ciência natural fornece o paradigma } \\
\text { teórico para a correta focalização de } \\
\text { todos os assuntos e questões suscitados } \\
\text { pela realidade }\end{array}$ & $\begin{array}{l}\text { V. O estudo científico adequado das } \\
\text { associações humanas é um tipo de } \\
\text { investigação em si mesmo, distinto da } \\
\text { ciência dos fenômenos naturais, e mais } \\
\text { abrangentes que esta }\end{array}$ \\
\hline
\end{tabular}

FONTE: GUERREIRO RAMOS, 1989, p.29. 
Se a razão para os gregos antigos aparece como parte da estrutura da existência humana, como "[...] força ativa na psique humana" (GUERREIRO RAMOS, 1989, p.19), para os modernos, há um inevitável desdobramento identificado no quadro 1. Razão, na modernidade, associa-se aos movimentos de "fuga à incerteza", aos movimentos de exclusão dos espaços de criação ou renovação da substantividade. A razão moderna é desencantada, ela exclui mitos, paixões, emoções, sentimentos e fantasmas que ameacem sua hegemonia sobre as mentes dos homens. Em uma frase, a razão moderna, além de ser uma caricatura da razão substantiva dos gregos antigos, nada mais é que uma expressão direta da mente do homem moderno, pautada e condicionada pelo autointeresse.

\section{A Razão Moderna}

É deveras complicado elaborar respostas provisórias para indagações sobre a racionalidade moderna sem enfrentar seriamente o conceito de Razão. Na percepção de Guerreiro Ramos (1989, p.19), "o que se chama de razão, na sociedade centrada no mercado [...], é uma corruptela do termo tal como ele mesmo e seus equivalentes sempre foram universalmente entendidos até o limiar dos tempos modernos". A substantividade tende a desaparecer "[...] num mundo em que o cálculo utilitário de consequências passa a ser a única referência para as ações humanas".

Para complementar sua análise crítica da racionalidade moderna, Guerreiro Ramos recorre ao ilustre sobrinho de Durkheim, Marcel Mauss, que afirma serem as sociedades ocidentais as principais responsáveis pela transformação do homem em animal econômico, "numa criatura que age, de acordo com o caráter - ethos utilitário, imanente às organizações formais de hoje" (GUERREIRO RAMOS, 1989, p.123).

Mais adiante, seguindo os passos de Arendt, Guerreiro Ramos explica que, face à lógica de mercado, o animal laborans eleva-se à posição antes ocupada pelo animal rationale (ARENDT, 1989). No diálogo de Guerreiro Ramos com Arendt, o animal humano, que se distingue dos outros animais não por andar sob dois pés e se organizar em bando, mas por saber educar suas vontades e paixões, na modernidade é reduzido a um ser vivente com a capacidade única de realizar cálculos unidimensionais. Eis a trágica transformação da razão substantiva em 
racionalidade instrumental. No domínio das teorias da administração, as organizações formais da era moderna passam a incluir apenas "parcialmente" (KATZ e KAHN, 1987) os seres humanos em seus quadros operacionais, admitindo explicitamente serem estes máquinas "comportamentais". No novo "paraíso" chamado mercado as almas das pessoas passam a ser compradas e vendidas como se fosse este um processo "natural".

A teoria do valor, presente nas formulações clássicas da economia política, deixa de ser uma particularidade da ideologia que legitima a sociedade centrada no mercado para se transformar em dimensão "universal" da natureza humana. A teoria do valor emerge a partir de Hobbes (1980), de reformadores religiosos tais como Lutero e Calvino, e de moralistas como Bentham, todos responsáveis pela elaboração de um ethos utilitário, fundante de uma ética do trabalho. A ética do trabalho apoia-se na premissa de que o trabalho é o critério mais sublime de valor porque é capaz de exercer domínio quase que absoluto sobre a existência social e individual. Neste particular, diante da nova ética do trabalho, a antiga separação entre trabalho e ocupação torna-se ameaçadora para o mercado; precisa ser desfeita radicalmente. Os conflitos e as tensões substantivas, ambos próprios da psique humana, tornariam inviável o sistema de mercado. Sem a crença disseminada e universalizada em

"[...] um tipo específico de socialização, através do qual o indivíduo internaliza profundamente o caráter - ethos - do mercado, e age como se tal caráter fosse o supremo padrão normativo de todo o espectro de suas relações interpessoais" (GUERREIRO RAMOS, 1989, p.142),

o sistema de mercado não teria o êxito que teve ao longo dos últimos 300 anos.

Em síntese, numa sociedade centrada no mercado, logo unidimensionalizada, ocorre a perversão programada da emocionalidade humana, à medida que o indivíduo é educado para expressar mal ou precariamente seus sentimentos e emoções. Cumpre notar que a citada perversão da emocionalidade torna-se fato não porque o mercado é "mau" em si mesmo, mas porque a substantividade aparece como ameaça perene à lógica excludente e de acumulação que sustenta o sistema capitalista em seu conjunto. 


\section{A Racionalidade Substantiva}

A racionalidade substantiva possibilita a preservação de aspectos fundamentais e permanentes da existência humana que a sociedade centrada no mercado ainda não conseguiu colonizar, deformar ou destruir. A racionalidade substantiva, além de se configurar como alternativa teórica, configura-se igualmente como um manifesto contra teorias sociais fundamentadas na racionalidade instrumental.

Na perspectiva de Guerreiro Ramos, o ponto de partida para a construção de uma racionalidade substantiva é a mente humana. O autor destaca que "a racionalidade substantiva sustenta que o lugar adequado à razão é a psique humana. Nessa conformidade, a psique humana deve ser considerada o ponto de referência para a ordenação da vida social" (GUERREIRO RAMOS, 1989, p.23).Diferente de muitas abordagens presentes nas ciências sociais, que aceitam a racionalidade como dimensão inerente aos processos históricos, Guerreiro Ramos fundamenta sua abordagem na psique humana. Em seu diálogo com Weber, o autor destaca que o sociólogo alemão não desenvolve sua análise da vida social a partir da racionalidade substantiva. Para Guerreiro Ramos, embora admita a importância da substantividade humana, embora faça a distinção esclarecedora entre Zweckrationalität (racionalidade formal) e Wertrationalität (racionalidade substantiva), Weber constrói sua teoria social a partir da racionalidade instrumental, deixando em plano secundário, ou em aberto para estudos futuros, a racionalidade substantiva. Isto significa admitir que "[...] uma teoria substantiva poderia ser formulada com base naquilo que Weber não disse" (GUERREIRO RAMOS, 1989, p. 25) e, nesse sentido, é possível inferir que Guerreiro Ramos e Leff (1994 e 2000), cada qual com suas singularidades, conseguem completar a lacuna deixada pelo sociólogo alemão, ao proporem abordagens da "racionalidade substantiva" e da "racionalidade ambiental", respectivamente.

Seguindo a tradição de pensamento inaugurada por Platão (1999) e Aristóteles (1999), mas dialogando com Weber e com a teoria social, Guerreiro Ramos (1989, p.16) sustenta que

a racionalidade, no sentido substantivo, nunca poderá ser um atributo definitivo da sociedade, pois é diretamente apreendida pela consciência humana, não pela mediação social. Ela impele o indivíduo na direção de um 
esforço contínuo, responsável e penoso para dominar suas paixões e suas inclinações inferiores.

É a mesma linha de raciocínio seguida por Voegelin, ao afirmar que "a esperança de um estágio social definitivo, perfeito e harmonioso, é vã" (VOEGELIN apud GUERREIRO RAMOS, 1989, p.17). Para Guerreiro Ramos, só é possível pensar em autorrealização humana por meio "[...] de uma mudança no íntimo das pessoas, em sua orientação relativamente à realidade e nos critérios de percepção e definição de suas necessidades e desejos" (GUERREIRO RAMOS, 1989, p.42). Percebe-se que, tal como Beck (1997), Gorz (1988), Touraine (1994), Guerreiro Ramos já identificava que as ciências sociais clássicas não mais conseguiam explicar o momento contemporâneo a partir da década de 1960. Daí sua insistência na ideia de que "[...] não é a [...] história que nos permite sermos inteligíveis e inteligentes. Antes, é a razão, em sentido substantivo, que capacita os seres humanos a compreenderem as variedades históricas da condição humana" (GUERREIRO RAMOS, 1989, p.46). Ao optar por tal perspectiva, Guerreiro Ramos rejeita toda e qualquer explicação ou visão que seja determinista tanto do ponto de vista da natureza quanto da sociedade.

Tentando escapar dos determinismos, na abordagem substantiva da racionalidade há uma mudança de eixo, à medida que atualização e autorrealização humana aparecem como dimensões consideradas não necessariamente incompatíveis diante da conduta racional calculista. Em função disto, é oportuno recordar que antes da experiência moderna, falar de sociedade racional pressupunha "fidelidade a um padrão objetivo de valores postos acima de quaisquer imperativos econômicos" (GUERREIRO RAMOS, 1989, p.122). Esta orientação da vida associativa a partir de valores que transcendem ou diferenciam-se dos imperativos econômicos é uma das tentativas de delimitar os sistemas sociais, sobretudo quando Guerreiro Ramos afirma que "raramente se podem integrar atualização pessoal e maximização da utilidade, no sentido estritamente econômico" (GUERREIRO RAMOS, 1989, p.142). O autor utiliza "raramente" porque reconhece o poder "colonizador", constitutivo da racionalidade instrumental.

Em síntese, a abordagem de Guerreiro Ramos conduz o leitor para a elaboração de um modelo paraeconômico, no qual "[...] os recursos são infinitos e não há limites ao crescimento" (GUERREIRO RAMOS, 1989, p.181). Em sentido 
oposto das conclusões neomalthusianas do famoso "relatório Meadows" (1974), nos termos paraeconômicos, não faz sentido falar em "limites de crescimento", muito menos em "crescimento zero" (MEADOWS, 1978), pois "[...] há abundância de recursos e substancial capacidade produtiva que permanecem ociosas graças à falta de adequado esquema teórico para organização dessas potencialidades" (GUERREIRO RAMOS, 1989, p.181). Em uma frase, Guerreiro Ramos insiste na mesma questão: a razão humana é a base tanto dos problemas quanto das possíveis soluções para as infinitas tensões e ambigüidades presentes nas mais diversas experiências associativas. Os elementos constituintes e constitutivos da crise $^{3}$ contemporânea não podem ser buscados na racionalidade substantiva, mas na racionalidade instrumental.

\section{A Racionalidade Ambiental}

Se a racionalidade substantiva, na perspectiva de Guerreiro Ramos, está centrada fundamentalmente na psique humana, na interpretação de Leff (1994, p.18) a racionalidade ambiental aparece como "un proceso de producción teórica, desarrollo tecnológico, cambios institucionales y transformación social”. Para construir seu arcabouço teórico, Leff (1994, p.18) parte de três aportes consagrados na ciência social: "el concepto de formación socioeconómica en Marx, el concepto de racionalidad en Weber y el concepto de saber en Foucault".

Em seu afã de apreender e reelaborar as explicações envolvendo processos sociais e a complexa problemática ambiental, Leff (1994 e 2000) não hesita em acentuar - tal como Beck (1997), Gorz (1988), Touraine (1994) e Guerreiro Ramos (1989) - as evidentes descontinuidades entre a questão ambiental, social por excelência, e as ciências sociais, incapazes ou resistentes às necessárias modificações de fundo que precisam ser feitas nos seus conceitos explicativos. O autor admite que os métodos e teorias das ciências sociais atingiram seus limites, tornando-se insuficientes para explicar "[...] las relaciones entre estos procesos sociales y los cambios ambientales emergentes" (LEFF, 1994, p.19).

3 Crise em sentido próximo ao de Leff (1994 e 2000), como crise civilizatória e com rebatimentos perversos sobre todos os domínios da vida associativa. 
Ao que parece, a crítica de Leff (1994) às ciências sociais formais é idêntica à de Guerreiro Ramos no que diz respeito à submissão delas aos ditames do mercado. Em seus próprios termos,

[...] la conexión entre lo social y lo natural se há limitado al propósito de internalizar normas ecológicas y tecnológicas a las teorías y las políticas económicas, dejando al margen el análisis del conflicto social y el terreno estratégico de lo político que atraviesan el campo de lo ambiental (LEFF, 1994, p.19).

Mais adiante, discutindo em termos similares ao debate de Guerreiro Ramos sobre a necessidade de delimitação dos sistemas sociais, Leff (1994, p.20) afirma que

[...] la construction de una racionalidad ambiental es un proceso político y social que pasa por la confrontación y concertación de intereses opuestos, por la reorientación de tendencias (dinámica poblacional, racionalidad del crecimiento económico, patrones tecnológicos, práticas de consumo); por la ruptura de obstáculos epistemológicos y barreras institucionales; por la creación de nuevas formas de organización productiva, la innovación de nuevos métodos de investigación, y la producción de nuevos conceptos y conocimientos.

Fica evidenciado que a racionalidade ambiental não emerge por decreto. Trata-se de uma construção lenta, mas progressiva e persistente. É conduzida por setores dispostos e sensibilizados acerca da necessidade imperativa de delimitar ou frear a dimensão colonizadora da racionalidade instrumental. Ao ser caracterizada como processo político e social, a racionalidade ambiental aparece como possibilidade objetiva de ampliação dos espaços reservados à autorrealização humana, negados historicamente pela excessiva instrumentalidade da lógica de mercado.

No estágio em que se encontram as ciências sociais, Leff (1994, p.22-3) as apresenta como obstáculos, dadas suas limitações, ao avanço da racionalidade e do saber ambiental. $O$ autor destaca que

\footnotetext{
la rigidez y el apriorismo de la ciencia social, impiden captar la causalidad sociológica de los problemas ambientales y los procesos de cambio social que están en germen en la ética y en los objectivos del movimiento ambientalista, obstaculizando una praxeología que oriente al movimiento ambiental hacia la construcción de una nueva racionalidad social.
} 
O trecho revela que a despeito de seus discursos supostamente emancipatórios, as ciências sociais permanecem "encantadas" em um isolamento perverso que as condena a discursar para si mesmas como se nada estivesse acontecendo em seu entorno. A continuar no isolamento, as ciências sociais correm o risco de tornarem-se ventríloquas. Contudo, a despeito de suas reservas face aos limites das ciências sociais, Leff (1994) está atento as suas potencialidades latentes e reconhece que nenhuma teoria produz por si mesma o conhecimento. A teoria, seja ela qual for, apenas ajuda a iluminar a mente de quem a utiliza em busca, aí sim, da construção do conhecimento. Tais esclarecimentos ajudam a entender porque Leff (1994, p.24) recorre a Marx, Weber e Foucault para elaborar seu arcabouço teórico. De Marx, o autor se apropria do conceito de formação socioeconômica:

[...] la teoría marxista se abre [...] a una percepción de las conexiones entre sociedad y naturaleza a partir de la centralidad (de la determinación en última instancia) de la producción material y de los procesos económicos.

A ênfase no processo produtivo e econômico é apreendida por Leff (1994) como possibilidade de construção de uma teoria crítica da sociedade. $\mathrm{O}$ autor acentua que o desenvolvimento das forças produtivas, orientadas por valores que transcendam à lógica de mercado, possibilita aberturas de espaços para a autorrealização humana.

Algumas dificuldades aparecem na formulação de Leff (1994). O conceito de formação socioeconômica de Marx, por ter como núcleo o processo material de produção, tem dificuldades para explicar sistemas culturais não centrados no mercado. Para resolver tais insuficiências, Leff (1994) acrescenta variáveis culturais, não hesitando em utilizar contribuições da antropologia. Ou seja, o autor está atento ao fato de que em sociedades "primitivas" o centro não é o mercado, mas as relações de parentesco, vizinhança, religião etc.

Sendo assim, a racionalidade ambiental de Leff (1994) constitui-se a partir do princípio da articulação entre sistemas (materiais e imateriais) e deve assegurar

[...] condiciones de sustentabilidad ecológica, sino que genere un potencial ambiental de desarrollo a partir de los principios materiales de una productividad ecotecnológica, fundada en la articulación de los niveles de productividad cultural, ecológica y tecnológica que genera una formación socioambiental (LEFF, 1994, p.30). 
Cumprida a etapa de articulação entre sistemas materiais e imateriais, Leff (1994, p.32) se aproxima de Weber, com vistas a se apropriar do conceito de racionalidade. $\mathrm{O}$ autor destaca que

[...] el concepto de racionalidad en Weber abre a importantes perspectivas al análisis de la problemática ambiental [...] porque permite pensar de manera integrada los diferentes procesos sociales que dan coherencia y eficacia a los principios materiales y a los valores culturales que organizan a una formación social ambientalmente sustentable.

Em sua análise da ação humana, Weber destaca a noção de "la significación vivida o de sentido subjetivo" (LEFF, 1994, p.32). Com tal estratégia, Weber

[...] abre así la posibilidad de incorporar al estudio de la racionalidad social una multiplicidad de motivaciones y fuerzas sociales de cambio para analizar la transición hacia una sociedad construida sobre los valores del ambientalismo (LEFF, 1994, p.32).

Ao contrário de Guerreiro Ramos, que afirma ser Weber um adepto resignado da racionalidade instrumental, Leff (1994, p. 33) assevera que a teoria de Weber é fértil para pensar e inovar a substantividade humana, pois

[...] con el concepto de racionalidad sustantiva, Weber rechaza la validez de una jerarquia universal de fines, contraponiendo la diversidad de valores y estableciendo la inconmensurabilidad de fines y medios entre diferentes racionalidades.

A posição favorável de Weber ao pluralismo cultural é o ponto de partida para Leff (1994, p.33) compor "[...] los principios de pluralidad política y diversidad cultural del ambientalismo".

Daí decorre a formulação do conceito de racionalidade

como um sistema de valores, normas, acciones y relaciones de medios y fines, que permite analizar la coherencia de un conjunto de procesos sociales que se abren a la construcción de una teoría de la producción y la organización social, fundada en los principios del ecodesarrollo, de la gestión ambiental y el desarrollo sustentable (LEFF, 1994, p.33).

Ao contrapor substantividade e instrumentalidade, Leff (1994), de forma indireta, aproxima-se da noção de que é necessário e fundamental delimitar os sistemas sociais, sobretudo o sistema econômico, por meio de uma racionalidade ambiental, que se apoia em valores e avanços que (re)constituem no interior da 
sociedade civil. A racionalidade ambiental seria o freio para a dimensão colonizadora da lógica de mercado. Em suas próprias palavras,

[...] la constitución de una racionalidad social fundada en los principios de la gestión ambiental y del desarrollo sostenible, pasa por procesos de transformación de la racionalidad económica dominante, así como de las instituciones y los aparatos ideológicos que la sustentan y legitiman (LEFF, 1994, p.34).

Ao que parece, o autor faz alusão a um sistema de mercado funcionando, mas controlado, isto é, delimitado por outra racionalidade, diversa da racionalidade instrumental. Seguindo a lógica do raciocínio, a racionalidade ambiental tem pretensões de se caracterizar como "racionalidade productiva alternativa", mas capaz de privilegiar espaços para a autorrealização humana. $\mathrm{O}$ autor destaca que

[...] la racionalidad ambiental no es la expresión de una lógica (del mercado, de la naturaleza) o de una ley (del valor, del equilibrio ecológico); es la resultante de un conjunto de normas, intereses, valores, significaciones y acciones que no se dan fuera de las leyes de la naturaleza y de la sociedad, pero que no las imitan simplemente. Se trata de una racionalidad conformada por procesos sociales que desbordan a sus actuales estructuras (LEFF, 1994, p.37).

Leff tem claro que nenhum ecossistema natural ou social sobrevive a uma lógica única. Isso fica evidente ao admitir que a racionalidade ambiental não pode ser definida a partir de um único centro ou núcleo. Ela é, por definição, multicêntrica. Ao se referir à dimensão multicêntrica da racionalidade ambiental, Leff aproxima-se da mesma perspectiva de Guerreiro Ramos ao esboçar seu conceito de racionalidade substantiva. Na formulação de Leff (2000, p.31),

[...] os conhecimentos e os saberes jogam um papel instrumental ao potencializar a apropriação econômica da natureza; mas também jogam como saberes que forjam sentidos e que mobilizam a ação com valores não mercantis e para fins não materiais nem utilitários.

Percebe-se que a racionalidade ambiental deriva de um saber ambiental. Como este último está à margem do mercado, a racionalidade ambiental também não pode ser refém da instrumentalidade do mercado. Neste particular, Leff é um rastreador da racionalidade substantiva à medida que admite que a racionalidade instrumental do mercado, além de submeter a natureza aos seus desígnios dominadores, extermina a complexidade e subjuga os "saberes não científicos", não 
ajustáveis à lógica dominante. Ao avançar na crítica da racionalidade instrumental, Leff afirma que

[...] as causas profundas da crise ambiental - e suas manifestações nas diferentes 'problemáticas ambientais' - remetem a um questionamento da racionalidade que as gera e à construção de uma nova racionalidade (LEFF, 2000, p.36).

Ao que parece, sempre que ele faz menções a uma nova racionalidade, está admitindo que as possíveis soluções para a crise ambiental precisam ser buscadas na substantividade humana. Em seus próprios termos,

[...]a construção de uma 'racionalidade ambiental' demanda também a interdisciplinaridade, mas não só como um método integrador do existente, senão como uma perspectiva transformadora dos paradigmas atuais do conhecimento, da abertura à hibridação das ciências, das tecnologias e dos saberes populares. Nesse sentido, a racionalidade ambiental estabelece bases materiais e princípios conceituais para a construção de uma nova economia fundada no potencial ambiental que produz a sinergia dos processos ecológicos, tecnológicos e culturais (LEFF, 2000, p.36).

Com a mente voltada para o processo de "reencantamento" das ciências sociais, Leff rejeita qualquer empreitada que conduza a possíveis "reservas de mercado" no que tange às soluções dos problemas ambientais, pois

[...] os processos de transformação dos ecossistemas não dependem tãosomente das leis biológicas da evolução, senão que são afetados e sobredeterminados pela apropriação cultural e econômica dos recursos naturais. A racionalidade econômica não pode integrar-se no objeto da ecologia (LEFF, 2000, p.40).

Além de admitir que não cabe exclusivamente à biologia resolver os problemas ambientais, admite também a incompatibilidade entre racionalidade instrumental e racionalidade ambiental. Em sua visão, a incompatibilidade está associada às diferenças de temporalidades no que diz respeito à apropriação dos recursos naturais e a renovação dos mesmos recursos. Dessa perspectiva, sob a égide da racionalidade instrumental, a velocidade de apropriação ultrapassa, a passos largos, o tempo de renovação dos recursos, desencadeando e aprofundando as crises socioambientais.

A percepção da crise exige um diálogo entre saberes, evidenciando mais uma vez os limites das ciências clássicas. O autor destaca que "[...] não será possível resolver a crise ambiental mediante uma administração científica da natureza, já que 
toda intervenção e apropriação da natureza implicam estratégias de poder no saber" (LEFF, 2000, p.45). Com isso, Leff (2000) admite que o "saber ambiental" é um saber híbrido, pois articula conhecimentos científico-tecnológicos com saberes práticos "tradicionais". É a tese do reencantamento do mundo, da abertura epistemológica para novos campos de saberes. Trata-se de um chamamento de tudo que foi expulso da ciência formal, como folclores, mitos, lendas etc.

Finalmente, a racionalidade ambiental

[...] confronta, assim, o logocentrismo da ciência positivista, a racionalidade formal e instrumental da modernidade e o projeto de interdisciplinaridade teórica e técnica que busca recompor essa lógica fundacional da civilização moderna. A racionalidade ambiental chama à construção de um saber fundado em uma constelação de diversidades arraigadas na cultura e na identidade (LEFF, 2000, p.47).

Em outros termos, Leff está afirmando que a racionalidade ambiental não pode ser expressão direta da racionalidade econômica do mercado. A dimensão colonizadora e monológica da racionalidade instrumental é incompatível com a dimensão emancipatória e dialógica da racionalidade ambiental. Esta última possibilita a delimitação do sistema econômico, atuando como freio aos possíveis abusos da lógica instrumental.

\section{Considerações Finais}

Em primeiro lugar, vale a pena destacar e ressaltar que a principal reivindicação de Guerreiro Ramos é que só existe uma Razão, a ser entendida como força ativa na psique humana. Em segundo lugar, a era moderna degradou a razão, em seu sentido substantivo, reduzindo-a à dimensão calculista da mente humana. Isso significa que a noção de racionalidade predominante nos últimos 300 anos, diante do processo de "desencantamento" do mundo, descolou-se de sua dimensão substantiva, deixando esta à deriva. Note-se que a substantividade, face uma civilização orientada pelo produtivismo, torna-se uma ameaça constante. Em terceiro lugar, por mais que se tente, é impossível eliminar por completo a racionalidade substantiva, pois seu aniquilamento implica erradicação total do ser humano. Em função disto, a racionalidade substantiva, embora marginalizada ao longo da era moderna, aparece como rota de fuga para muitos excluídos, mas 
também como limite ético para os abusos inevitáveis da racionalidade instrumental. A racionalidade substantiva, portanto, pressupõe a delimitação dos sistemas sociais, sobretudo do econômico, como possibilidade objetiva de garantir e ampliar espaços para a autorrealização humana.

Por último, o conceito de racionalidade ambiental, ao se apoiar no saber ambiental, supõe a delimitação dos sistemas sociais. Para tanto, mesmo não se descolando da perspectiva produtivista, pois a racionalidade ambiental apresenta-se como mais uma estratégia alternativa de produção da existência humana, emerge com a novidade de incorporar fatores culturais, imaginários e outros, antes desprezados ou desconsiderados nas formulações clássicas, reféns da racionalidade instrumental.

Leff (1994 e 2000) tem claro que seria pouco sustentável a idéia de fazer derivar uma racionalidade ambiental de um estilo civilizatório estribado na racionalidade instrumental. Da mesma forma que Guerreiro Ramos, Leff (2000, p.28) critica todas as formulações dentro dos estudos ambientais que se subordinam a uma "[...] racionalidade científica que tem 'externalizado' o ambiente e que desconhece o saber ambiental". O autor destaca que a homogeneização dos saberes é um grande equívoco, pois não é possível desconsiderar a especificidade conceitual de cada um deles, dentro dos limites de cada território onde foram historicamente construídos.

A questão central, a ser aprofundada em novas pesquisas, é identificar nos sistemas socioculturais racionalidades alternativas que, embora admitam a importância da racionalidade instrumental, não estejam centradas nela. Salta aos olhos que tanto os sistemas socioculturais centrados no mercado, quanto as teorias que se propõem a explicá-los, amparadas em categorias também centradas no mercado, esbarram em limites quase intransponíveis. Portanto, a busca de alternativas epistêmicas, teóricas e metodológicas, presentes nas formulações de Guerreiro Ramos e Leff, ao enfrentarem a complexidade da crise da contemporaneidade, dão pistas para a compreensão de que os elementos constitutivos da crise são fundamentalmente civilizatórios, pois rebatem em todos os domínios da vida associativa. 


\section{REFERÊNCIAS}

ARENDT, H. A condição humana. Rio de Janeiro: Forense Universitária, 1989.

ARISTÓTELES. Ética a Nicômaco; Poética. Seleção de textos de José Américo Motta Pessanha. São Paulo: Editora Nova Cultural, 1987. (Coleção Os Pensadores).

BECK, U. Modernização reflexiva: política, tradição e estética na ordem social moderna. São Paulo: Ed.Unesp, 1997.

GORZ, A. Métamorphoses du travail quête du sens: critique de la raison économique. Galilée, 1988.

GUERREIRO RAMOS, A. A nova ciência das organizações: uma reconstrução da riqueza das nações. 2.ed. Rio de Janeiro: Editora da FGV, 1989.

HOBBES, T., Leviathan, livro II. São Paulo: Abril Cultural, 1980. (Coleção Os Pensadores).

KATZ, D.; KAHN, R. L. Psicologia das organizações. 3.ed. São Paulo: Atlas, 1987.

LEFF, E. Complexidade, interdisciplinaridade e saber ambiental, in: PHILIPPI Jr., A.; TUCCI, C. M.; HOGAN, J.; NAVEGANTES, R. (Editores). Interdisciplinaridade em Ciências Ambientais, São Paulo, Signus Editora, 2000.

LEFF, E. Sociogía y ambiente: formación socioeconómica, racionalidad ambiental y transformaciones del conocimiento, in: Ciencias Sociales y formación ambiental, Gedisa Editorial, Barcelona, 1994.

MEADOWS, D. L. Limites do crescimento. 2.ed. São Paulo: Perspectiva, 1978. PLATÃO. Banquete. São Paulo: Abril Cultural, 1999. (Coleção Os Pensadores).

POLANYI, Karl. A grande transformação: as origens da nossa época. Tradução de Fanny Wrobel. 3.ed. Rio de Janeiro: Campus, 1980.

POLANYI, Karl. El sustento del hombre. Barcelona: Biblioteca Mondadori, 1994. 
RODRIGUES, José Albertino (org.). Durkheim. 4.ed. São Paulo: Ática, 1988. (Coleção Grandes Cientistas Sociais, v. 1).

SMITH, A. Uma Investigação sobre a Natureza e Causas da Riqueza das Nações. São Paulo: Editora tecnoprint, 1986.

TOURAINE, A. Crítica da Modernidade. Petrópolis: Vozes, 1994.

Artigo:

Recebido em: 21/09/2011

Aceito em: 19/06/2012 